\title{
Urgencias torácicas en el niño: rol de las imágenes
}

\author{
KARLA MOËNNE B.*
}

\section{Chest emergencies in children. Role of images}

Thoracic trauma and medical conditions with risk of severe respiratory impairment may be an emergency in pediatric age. The management of these children often involves quick decisions that require the most accurate diagnosis as it is possible; the images are an important tool in the diagnosis and management of these children. Chest X-ray is usually the first examination in most patients. Computed tomography fastly evidences pathological compromise with great precision, but is usually reserved for complex cases due to the radiation dose involved. This review highlights the role of images on: chest trauma, foreign body airway, spontaneous pneumothorax, pulmonary tromboembolism and acute asthma.

Key words: Chest emergencies, Thoracic trauma, Children, Images.

\section{Resumen}

El trauma torácico y patologías médicas que presentan riesgo de comprometer severamente la función respiratoria, pueden constituir una emergencia en la edad pediátrica. El manejo de estos niños involucra muchas veces rápidas decisiones, que requieren un diagnóstico lo más certero posible; las imágenes constituyen una importante herramienta en el diagnóstico y toma de decisiones terapéuticas. La radiografía de tórax es habitualmente el primer examen en la mayoría de estos pacientes; la tomografía computarizada que permite evidenciar con gran precisión y rapidez los cuadros patológicos involucrados, se reserva habitualmente para casos complejos, debido a la dosis de radiación que implica. En esta revisión se incluye el trauma torácico, cuerpo extraño en vía aérea, neumotórax espontáneo, crisis asmática y tromboembolismo pulmonar, destacando el rol de las imágenes en cada una de estas patologías.

Palabras clave: Urgencias torácicas, Trauma, Niños, Imágenes.

\section{Introducción}

Múltiples cuadros patológicos torácicos pueden constituir una emergencia en las distintas etapas de la vida de los niños, incluyendo eventos traumáticos y patologías médicas que comprometen severamente la función respiratoria o constituyen potenciales causas de desviaciones del mediastino, que pueden conducir a compromiso ventilatorio y hemodinámico progresivo. En todos ellos las imágenes forman parte importante de las herramientas diagnósticas necesarias para permitir un adecuado tratamiento, que muchas veces involucra decisiones rápidas para las cuales es necesario un diagnóstico lo más certero posible. Para esta revisión hemos seleccionado algunos de estos cuadros patológicos, en base a su frecuencia y/o relevancia en la práctica pediátrica.

\section{Trauma torácico}

Después del traumatismo cráneo-encefálico, constituye la segunda causa de muerte por trauma en la edad pediátrica ${ }^{1,2}$; habitualmente en el contexto de traumatismos de alta energía que originan compromiso multiorgánico. En niños con lesiones traumáticas múltiples, la presencia de trauma torácico aumenta 20 veces la mortalidad en comparación con aquellos sin lesiones en el tórax. Los niños son afectados con mayor frecuencia en relación con las niñas (3:1).

El traumatismo cerrado o contuso es el más habitual $(85 \%)$, causado generalmente por acci-

* Radióloga Infantil; Depto de Imágenes, Clínica Las Condes. 

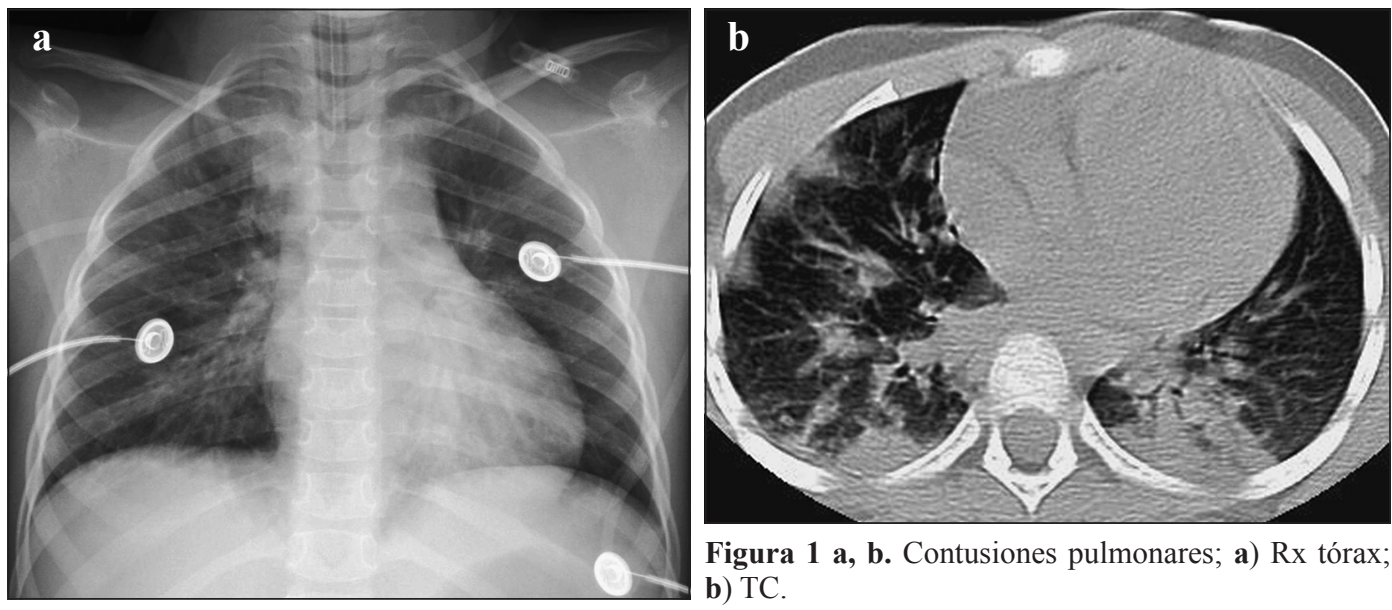

Figura 1 a, b. Contusiones pulmonares; a) Rx tórax; b) TC.

dentes automovilísticos, atropellos y caídas de altura $^{2}$; los traumas penetrantes son causados fundamentalmente por heridas de bala o arma blanca, muchas veces en riñas de adolescentes ${ }^{3}$. Las lesiones observadas varían según el mecanismo involucrado. En trauma contuso se observa predominantemente hemoneumotórax, contusiones pulmonares (Figura 1) y lesiones cardíacas; en los traumas penetrantes se producen laceraciones pulmonares, hemoneumotórax, lesiones cardíacas, diafragmáticas y vasculares.

El niño presenta características anatómicas propias que lo hacen responder al trauma de manera diferente a los adultos, destacando su menor tamaño corporal que origina mayor posibilidad de lesión de varios órganos; elasticidad de la pared torácica que posibilita la ocurrencia de lesiones intratorácicas en ausencia de fracturas costales; fijación laxa del mediastino, que permite grandes desplazamientos de éste, lo que asociado a la elasticidad de las paredes vasculares hace que las lesiones traumáticas de aorta sean mucho menos frecuentes ${ }^{2}$.

El retardo en el diagnóstico y los errores en la pesquisa de las lesiones traumáticas del tórax resultan en aumento de morbilidad y mortalidad. Lo más relevante para el diagnóstico es mantener un alto índice de sospecha clínica, en especial cuando existen otros traumatismos asociados en cráneo, abdomen o esqueleto, donde el examen físico puede ser poco confiable. Es necesario efectuar imágenes del tórax en todo niño con clínica sugerente de lesión torácica o con antecedente de trauma que involucre un mecanismo de alta energía.

La radiografía $(\mathrm{Rx})$ simple de tórax constituye un método de pesquisa accesible y de bajo costo, que evidencia alteraciones en 60 a $90 \%$ de los niños con lesiones torácicas importantes, por lo que se recomienda como evaluación inicial en la mayoría de los pacientes.

La utilización de la tomografía computarizada (TC), técnica rápida y confiable, ha ido aumentando progresivamente en las últimas décadas; se indica cuando existe el antecedente de trauma de alta energía con sospecha de lesiones en otros órganos, habitualmente cerebro y abdomen, incluyendo también el tórax en la adquisición helicoidal. Debe ser efectuada con medio de contraste endovenoso cuando se estudie el abdomen junto al tórax o, ante la sospecha de lesión vascular o contusión cardíaca ${ }^{3}$.

Aproximadamente el $90 \%$ de los niños con trauma torácico puede ser tratado de forma conservadora o mediante la instalación de un tubo de drenaje, por lo que la necesidad de intervención quirúrgica es poco frecuente en estos casos.

\section{Cuerpo extraño en la vía aérea}

La aspiración de cuerpos extraños (CE) a la vía aérea se observa especialmente en niños entre 6 meses y 3 años de vida, aunque también puede presentarse en niños mayores ${ }^{4}$. Su diagnóstico no siempre resulta fácil; el cuadro clínico más característico incluye historia de aspiración (síndrome de penetración), antecedente anamnésico que muchas veces no está presente cuando se trata de un niño pequeño. Los síntomas respiratorios pueden ser de poca duración, debido a que los receptores endobronquiales que inicialmente reaccionan al CE pierden su sensibilidad con rapidez ${ }^{5}$, por lo que éste puede permanecer alojado en la vía aérea por períodos prolongados, originando neumonías repetidas o presencia de sibilancias, habitual- 
mente unilaterales, que pueden ser interpretadas erróneamente como un cuadro asmático.

Se ha descrito una sensibilidad entre $68 \%$ y $75 \%$ para la Rx de tórax, con una especificidad entre $45 \%$ y $67 \%$ en la pesquisa de CE en la vía aérea; algunos autores han sugerido que todo niño en el que exista sospecha diagnóstica sea sometido a broncoscopia, procedimiento que por otra parte, tiene el riesgo de presentar falsos negativos en alrededor del $20 \%$ de los $\operatorname{casos}^{6}$. La TC aparece como la técnica de imágenes más sensible, aunque en general se la reserva para casos de difícil diagnóstico, por la dosis de radiación que involucra.

Las manifestaciones radiológicas de la presencia de un CE en la vía aérea dependerán de su localización y del tipo de objeto aspirado, que en su gran mayoría son de origen vegetal; pueden alojarse a cualquier nivel del aparato respiratorio, desde la nariz hasta la periferia del árbol bronquial, dependiendo de su tamaño y forma de penetración.

En la vía aérea alta -laringe y tráquea- un $\mathrm{CE}$ aspirado puede presentarse clínicamente en forma aguda con grave dificultad respiratoria, estridor e incluso apnea, lo que puede a veces hacer imposible la obtención de imágenes. En estos casos, la Rx puede demostrar una alteración simétrica de la aireación pulmonar asociada a prominencia cardíaca y mediastínica por disminución de la presión negativa intratorácica, signo radiológico sutil y difícil de apreciar. En forma ocasional, es posible visualizar directamente el CE por la diferencia de densidad con el aire de la vía aérea que lo rodea; el uso de TC resulta de gran utilidad en el diagnóstico de los cuerpos extraños en el interior de la tráquea.

En el momento del diagnóstico, la mayor parte de los CE aspirados están localizados en las ramas principales del árbol bronquial; como son mayoritariamente vegetales y por lo tanto, de baja densidad radiológica (radiolúcidos), no es posible visualizarlos directamente en $\mathrm{Rx} /$ radioscopia, por lo que el diagnóstico dependerá de signos indirectos, el más importante de los cuales es la alteración localizada del patrón de aireación normal del parénquima pulmonar por fenómeno valvular que condiciona el atrapamiento aéreo distal (Figura 2). La extensión de la alteración dependerá del bronquio comprometido, pudiendo observarse atrapamiento aéreo en todo un pulmón si el CE está en el bronquio fuente y lobar o segmentario si se localiza en los bronquios correspondientes. En aquellos alojados por un tiempo prolongado en la vía aérea puede observarse aparición de atelectasias, neumonías repetidas e incluso bronquiectasias, por lo que se sugiere considerar siempre la posibilidad de un $\mathrm{CE}$ en la vía aérea frente a cuadros respiratorios complejos, tanto en su aspecto clínico como en la evolución radiológica.

En niños mayores, al igual que en adultos, las características anatómicas del bronquio fuente derecho ofrecen una vía más expedita para que los CE se alojen con mayor frecuencia en este lado, debido a su disposición más vertical que el contralateral, con un ángulo más abierto en relación con la tráquea. En niños más pequeños, los bronquios tienen un aspecto anatómico bastante simétrico, por lo que no se aprecia diferencia estadística en cuanto a la frecuencia de localización a derecha o izquierda ${ }^{6}$. En TC se les pueden visualizar directamente, sean radiolúcidos o radioopacos, en el interior de la vía aérea y también se evidencia de excelente forma el atrapamiento aéreo distal al bronquio comprometido, se recomienda ésta como un método de alto rendimiento, que permite reducir el número de procedimientos endoscópicos negativos en los casos complejos ${ }^{4}$.

\section{Neumotórax espontáneo}

El neumotórax se define como presencia de aire en el espacio pleural. De acuerdo a su origen se clasifica en:

\section{Neumotórax primario o espontáneo (NE)}

Se relaciona con ruptura de pequeñas bulas o ampollas de localización subpleural. Es más frecuente en varones; en Estados Unidos e Inglaterra se describe una incidencia de 7,4 a 18 casos por

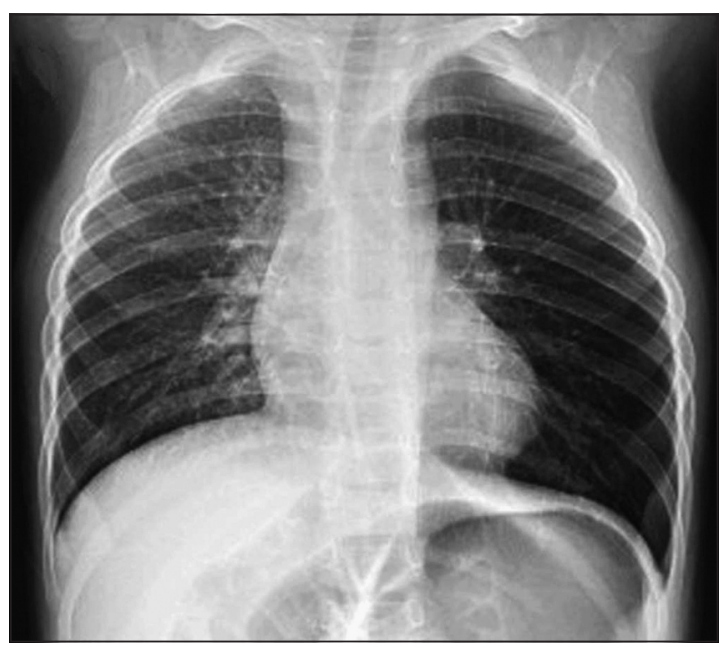

Figura 2. Rx de tórax: Atrapamiento aéreo en pulmón izquierdo y discreto desplazamiento mediastínico a derecha, secundario a cuerpo extraño vegetal en bronquio izquierdo. 
100.000 niños y 1,2 a 6 casos por 100.000 niñas ${ }^{7}$. En esta categoría también pueden incluirse los neumotórax "espontáneos" del período neonatal.

\section{Neumotórax secundario}

Se refiere a aquel que es causado por una patología preexistente o una lesión traumática que puede ser originada en ventilación mecánica (baro o volutrauma), iatrogenias y lesiones torácicas tanto contusas como penetrantes. Entre las patologías subyacentes observadas con mayor frecuencia destacan las enfermedades infecciosas, fibrosis quística y malformaciones pulmonares.

El NE se relaciona con la presencia de bulas subpleurales, localizadas a nivel de los ápices pulmonares en niños; en adultos se describe un $66 \%$ de bulas extra-apicales. El mecanismo fisiopatológico que origina la ruptura de las bulas no está totalmente aclarado. En niños se describe presencia en un $28 \%$ de bulas en TC y en adultos $56 \%$ en un primer episodio y $64 \%$ en un segundo evento; en el pulmón contralateral de los pacientes que presentan bulas, se pesquisan estas lesiones en el $78 \%$ cuando se trata de niños y en 15 a $66 \%$ en adultos ${ }^{7,8}$.

El diagnóstico se confirma habitualmente mediante Rx de tórax (Figura 3); la proyección de elección debe ser la placa frontal en bipedestación, cuando las condiciones clínicas del paciente lo permitan; cuando el diagnóstico resulte dudoso, es de utilidad adicionar una proyección complementaria en espiración. El signo radiológico más importante es la identificación de la línea pleural visceral, que limita el contorno entre el pulmón y el aire del espacio pleural. El parénquima pulmonar contiguo presentará diversos grados de colapso, dependiendo de la magnitud de la fuga aérea, y en los casos más graves puede aparecer como un pequeño muñón adyacente al hilio. Si la Rx se obtiene en posición de pie, pequeños volúmenes de aire del espacio pleural se ubicarán en la parte alta del hemitórax y configurarán una semiluna hipodensa que rodea el vértice pulmonar. En ocasiones existe aire y líquido en el espacio pleural, por lo que en posición de pie es posible observar aire en el vértice del hemitórax y nivel hidroaéreo, habitualmente pequeño, en la zona más baja del hemitórax. Si el examen se obtiene en decúbito, el aire pleural se localizará en la zona más anterior, por lo que el hemitórax comprometido aparecerá de mayor transparencia que el contralateral; con frecuencia el seno costofrénico ipsilateral se observará más pronunciado, lo que se denomina "signo del surco profundo", útil para reconocer la presencia de neumotórax en radiografías efectuadas en decúbito?
Cuando se trata de neumotórax de mayor tamaño, el hemitórax involucrado se observa aumentado de volumen e hiperlúcido y aparece un colapso pulmonar progresivo con grados variables de desplazamiento del mediastino. Inicialmente, éste se manifestará por un leve deslizamiento del corazón hacia el hemitórax contralateral, signo muchas veces sutil en etapas precoces y que se acentúa cuando el neumotórax se hace hipertensivo; en estos casos aparece además marcado descenso del hemidiafragma ipsilateral con aplanamiento e incluso inversión de su convexidad habitual. En las Rx frontales también es posible observar herniación del neumotórax, que se evidencia por una línea pleural que cruza anteriormente la línea media hacia el hemitórax contralateral.

La exacta indicación de la TC, sin contraste ev y el momento más adecuado para efectuarla, no están bien definidos en la literatura. Se utiliza para demostrar la presencia de bulas o ampollas tanto en el hemitórax comprometido como en el contralateral (Figura 4) y para descartar la presencia de otra patología pulmonar preexistente. En niños se describe que el $58 \%$ de las bulas existentes fueron identificadas en TC y en adultos este valor asciende a $88 \%$. Dado que en niños las bulas se disponen en los ápices pulmonares, se ha postulado focalizar la TC en los vértices ${ }^{8}$.

El manejo de los pacientes con NE es controversial y dependerá de muchos factores, entre los que su tamaño es muy importante. La valoración de éste se hace habitualmente en forma cualitativa, considerando el espesor del aire pleural, el

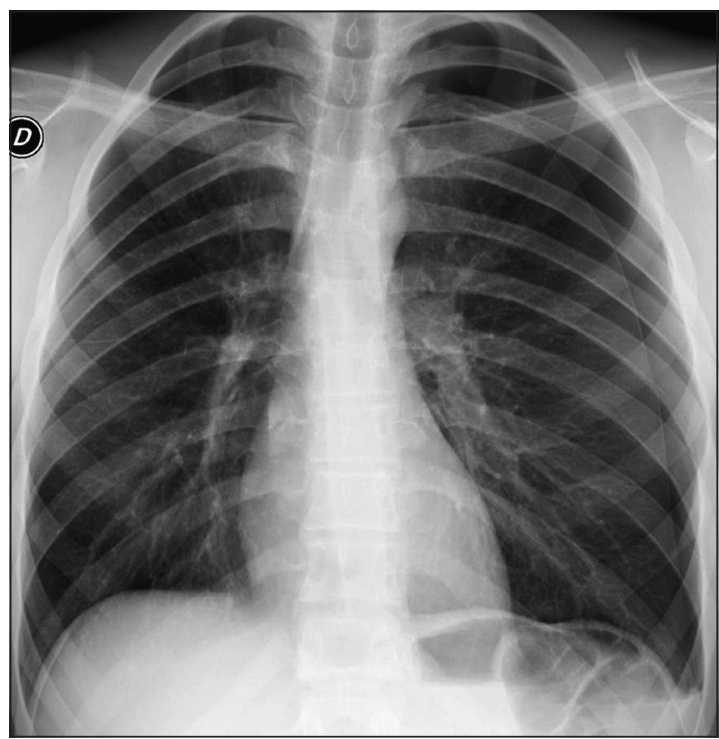

Figura 3. Rx tórax demuestra neumotórax espontáneo izquierdo, con discreta desviación del mediastino. 

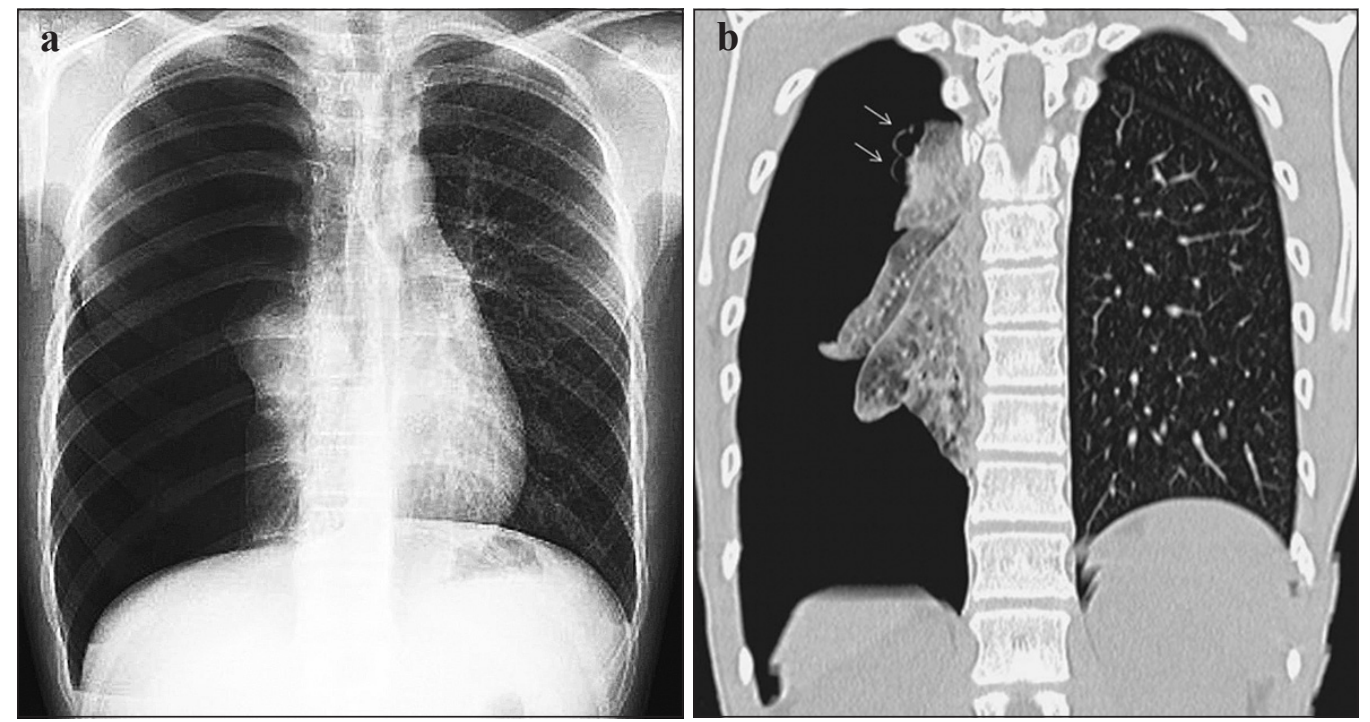

Figura 4 a, b. Neumotórax derecho y colapso pulmonar secundario; a) Rx tórax; b) Reconstrucción coronal de TC, evidencia bulas subpleurales en vértice del pulmón colapsado (flechas).

grado de colapso pulmonar y la posición del mediastino; se describe que si ocupa menos de $15 \%$ a $20 \%$ del hemitórax se considera como "menor" y requerirá escasa intervención terapéutica ${ }^{10}$; en los casos de mayor cuantía se utiliza drenaje pleural o tratamiento con videotoracoscopia.

El riesgo de recurrencia del NE en pacientes tratados con terapia conservadora varía entre 16 y $52 \%$. Por esta razón, para decidir el tipo de tratamiento se estima necesario considerar el estilo de vida del paciente, acceso a atención médica e incluso la opinión de la familia; se ha postulado tratamiento quirúrgico en el segundo episodio de NE y también cuando existen evidencias de bulas en el hemitórax contralateral ${ }^{8}$.

\section{Crisis asmática}

El asma se caracteriza por las siguientes condiciones que afectan la vía aérea:

- Obstrucción, habitualmente reversible.

- Inflamación crónica.

- Hiperreactividad no específica.

Puede ocurrir a cualquier edad pero la mayoría de los pacientes presentan sus primeros síntomas antes de los 5 años. Se manifiesta clínicamente por sibilancias periódicas y dificultad para respirar, de intensidad variable ${ }^{11}$.

El cuadro radiológico no es particularmente específico pero habitualmente incluye engrosamiento del intersticio peribronquial, asociado a diversos grados de hiperinsuflación pulmonar, esto último frecuente pero poco confiable en su evaluación a través de la Rx de tórax. Es necesario disminuir al mínimo las imágenes de estos niños, por la dosis de radiación involucrada, excepto cuando la evolución sea atípica o existan evidencias de una complicación; se sugiere que las Rx son innecesarias en pacientes con asma conocida que mejora con el tratamiento, a menos que se sospeche neumotórax o el paciente esté hospitalizado en una unidad de cuidados intensivos.

Las imágenes radiológicas son importantes para pesquisar las complicaciones agudas del asma, que incluyen: neumotórax, neumomediastino, impactaciones mucosas con/sin atelectasias y neumonías ${ }^{6,11}$. Habitualmente es la Rx de tórax la herramienta que permite identificar las complicaciones mencionadas o presencia de otros cuadros patológicos que pueden semejar el cuadro clínico de asma severa. En las crisis asmáticas, la presencia de atelectasias múltiples es muy frecuente (Figura 5) y se observan habitualmente grandes variaciones de éstas en controles sucesivos, que no deben sorprender al radiólogo ni al médico tratante. La TC puede demostrar con gran precisión las alteraciones mencionadas ${ }^{12}$ pero su uso es limitado en el cuadro agudo severo, por la condición clínica del paciente y la dosis de radiación que involucra.

\section{Tromboembolismo pulmonar}

El tromboembolismo pulmonar (TEP) es un diagnóstico poco frecuente en la edad pediátrica, que se define como obstrucción del flujo arterial 
pulmonar, ya sea por émbolos endógenos/exógenos o por trombos locales. Avances terapéuticos de los últimos años y en especial el mayor uso de catéteres venosos centrales han incrementado los TEP en niños, haciendo necesario un diagnóstico precoz, para minimizar las complicaciones, que pueden incluso llevar a la muerte del paciente, situación que se observa con mayor frecuencia en los adultos ${ }^{13}$.

Las imágenes resultan fundamentales en el diagnóstico, tanto para evitar errores diagnósticos como tratamientos inadecuados con terapia anticoagulante. Las recomendaciones para evaluar la sospecha de TEP en la edad pediátrica provienen de la experiencia en adultos, pese a que los niños tienen diferentes factores de riesgo y condiciones asociadas también distintas ${ }^{14}$. La incidencia en niños no es bien conocida, ya que lo publicado en diversas poblaciones pediátricas varía según índice de sospecha, enfermedades de base y pruebas diagnósticas utilizadas. Estudios de autopsia en niños muestran incidencias de TEP entre 0,73 y $4,2 \%$, dependiendo de las poblaciones analizadas. Se sabe que este cuadro se presenta con menor frecuencia en niños, debido a que existen factores protectores que incluyen: Reducida capacidad de generar trombina, mayor potencialidad de inhibir la trombina y mayor potencial antitrombótico de la pared de los vasos, entre otros. Si bien el TEP puede observarse a cualquier edad, se describe que lactantes y recién nacidos tienen mayor riesgo de trombosis, pero este diagnóstico muchas veces pasa desapercibido por la gran cantidad de cuadros patológicos concomitantes que se observan habitualmente en estos niños ${ }^{13}$.
El TEP frecuentemente ocurre en asociación con trombosis venosa profunda (TVP); habiéndose demostrado en un 30 a $60 \%$ de niños en los que la trombosis ha sido documentada. En pacientes pediátricos se describe mayor frecuencia de TEP cuando la TVP ocurre en el sistema venoso superior, a diferencia de los adultos. Entre los factores que representan un aumento del riesgo de trombosis vascular se mencionan; catéteres venosos, trombofilia o hipercoagulabilidad, neoplasias, malformaciones vasculares, cirugía ortopédica, enfermedad renal, alteraciones hematológicas y factores misceláneos ${ }^{13,14}$.

En niños con sospecha de TEP, el cuadro clínico es inespecífico y a veces también lo son los exámenes de laboratorio, razón por la cual se describe que muchas veces el diagnóstico pasa inadvertido hasta el momento de la autopsia.

En el estudio por imágenes, la Rx simple puede resultar normal o mostrar hallazgos inespecíficos. Las nuevas generaciones de tomógrafos computarizados multicorte han mejorado significativamente el diagnóstico no invasivo de TEP, que actualmente se hace mediante Angio-TC pulmonar con uso de medio de contraste yodado, por lo que se requiere de una buena función renal; los trombos se visualizan como defectos de llenamiento o falta de contraste en las ramas de la arteria pulmonar (Figura 6). Recientes progresos tecnológicos en resonancia magnética han permitido que esta técnica aparezca como una alternativa, sin necesidad de uso de radiación; en niños pequeños, el tiempo de examen y su costo constituyen factores que actualmente limitan su uso.
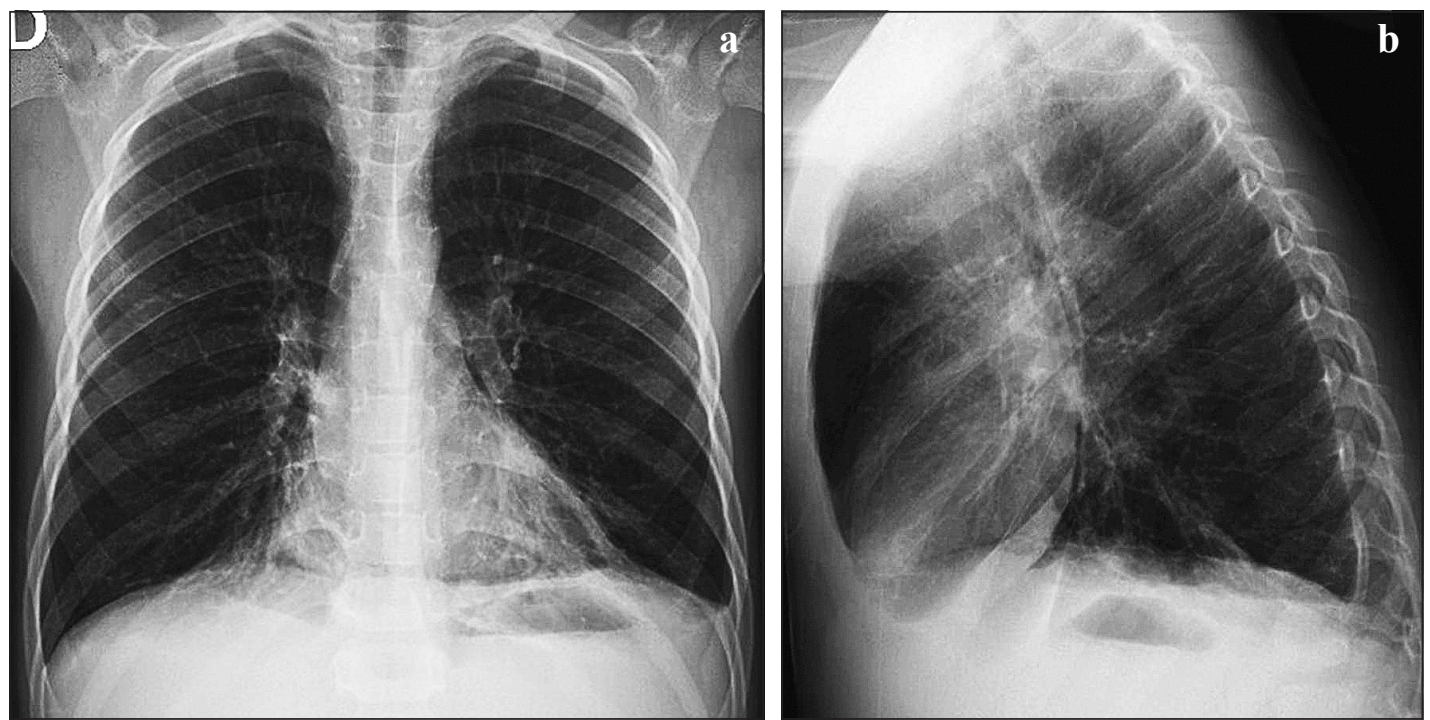

Figura 5 a, b. Crisis asmática: hiperinsuflación pulmonar y atelectasias bibasales. Rx de tórax AP (a) y lateral (b). 


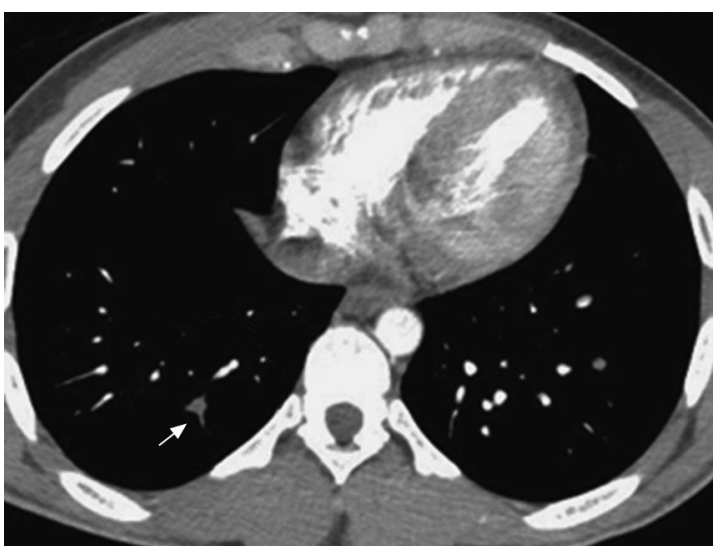

Figura 6. Tromboembolismo pulmonar: AngioTC pulmonar demuestra rama de arteria pulmonar sin contraste en campo pulmonar derecho.

\section{Conclusión}

Las imágenes juegan un importante rol en el diagnóstico de todas las urgencias torácicas en el niño. Es necesario conocer el rendimiento de cada uno de los exámenes disponibles para efectuar diagnósticos certeros con los métodos que signifiquen menor riesgo potencial para los pacientes pediátricos.

\section{Bibliografía}

1.- PITETTI R, WALKER S. Life-threatening chest injuries in children Pediatr Emerg Med 2005; 6: 16-22.

2. DONNELLY L F. Imaging issues in CT of blunt trauma to the chest and abdomen. Pediatr Radiol 2009; $39 \mathrm{Su}-$ ppl 3: 406-13.
3.- KAEWLAI R, AVERY L, ASRANI A, NOVELLINE R. Multidetector CT of blunt thoracic trauma. RadioGraphics 2008; 28: 1555-70.

4.- KUHN J. Diseases of the airways and abnormalities of pulmonary aeration. En: Caffey's pediatric diagnostic imaging. Philadelphia: Mosby; 2004; p. 944-8.

5.- BLAZER S, NAVEH Y, FRIEDMAN A. Foreign body in the airway: Review of 200 cases. Am J Dis Child 1980; 134: 68-71.

6.- MOËNNE K, ORTEGA X. Patología de la vía aérea, Cap 8 en Diagnóstico por imágenes del tórax pediátrico. Buenos Aires, Journal 2012. Pag. 126-32.

7.- SAHN S, HEFFNER J. Spontaneous Pneumothorax. N Engl J Med 2000; 342: 868-74.

8.- GUIMARAES C, DONNELLY L, WARNER B. CT findings for blebs and bullae in children with spontaneous pneumothorax and comparison with findings in normal age-matched controls.

9.- PÉREZ M, MOËNNE K, BITAR P. El signo del surco profundo. Rev Chil Radiol 2012; 18: 85-7.

10.- SHAW K, PRASIL P, NGUYEN L, LABERGE J. Pediatric Spontaneous Pneumotórax. Semin Pediatr Surg 2003; 12: 55-61.

11.- WOODS A, LYNCH D. Asthma: An imaging update. Radiol Clin N Am 2009; 47. 317-29.

12.- JENSEN S, LYNCH D, BROWN K, WENZEL S, NEWELL J. High-resolution CT features of severe asthma and bronchiolitis obliterans. Clin Radiol 2002; 57: 1078-85.

13.- BABYN P, GAHUNIA H, MASSOCOTTE P. Pulmonary thromboembolism in children. Pediatr Radiol 2005; 35: 258-74.

14.- VICTORIA T, MONG A, ALTES T, JAWAD A, HERNÁNDEZ A, GONZÁLEZ L, et al. Evaluation of pulmonary tromboembolism in a pediatric population with high clinical suspicion. Pediatr Radiol 2009; 39: $35-41$. 